\title{
Genetics of osmotic adjustment in breeding maize for drought tolerance*
}

\author{
ROBERT G. GUEI \& C. E. WASSOM $\dagger$ \\ WARDA 01 BP 2551, Bouake 01, Cote D'voire, West Africa and †Department of Agronomy, Kansas State University, \\ Manhattan, KS 66506-5501, U.S.A.
}

\begin{abstract}
Osmotic adjustment in higher plants refers to the maintenance of turgor by lowering of osmotic potential arising from the net accumulation of solutes in response to water deficits. Genetic variation for osmotic adjustment has been reported in several crops, but little is known about its inheritance and potential use as selection criteria in tropical maize (Zea mays L.). Two tropical lowland maize populations were used in this study to quantify the magnitude of genetic variability in osmotic adjustment; to estimate components of its genetic variance and heritability; and to determine the importance of this trait in breeding tropical maize for improved drought tolerance. Full-sibs within half-sib groups were developed using the Design I mating scheme and evaluated at two locations in Mexico for two seasons using water stress and non-stress environments. Results showed that in both populations, dominance genetic effects were more important than additive effects in controlling the expression of the trait. However, very little genetic variability was present in either population for the trait, although more genetic variation was detected with data collected at flowering stage, when water stress was more severe than at the vegetative stage. Non-significant phenotypic and genotypic correlations were found between osmotic adjustment and yield. Not much genetic gain could be expected from selection for osmotic adjustment in these populations.
\end{abstract}

Keywords: additive effects, dominant effects, drought tolerance, genetic variability, heritability, osmotic adjustment.

\section{Introduction}

Drought tolerance in plants is a complex trait and the mechanisms for expression and/or inheritance are not well understood. Several attempts have been made to combine physiological and morphological studies in maize to develop effective screening methods for drought tolerance. Selection criteria such as rates of tissue elongation, synchronization of male and female flowering, leaf canopy temperature, chlorophyll fluorescence, plant height, leaf area, osmotic adjustment, rate of foliar senescence and yield under drought stress have been used to screen for drought tolerance.

In higher plants, osmotic adjustment refers to the maintenance of turgor by lowering of osmotic potential, arising from the net accumulation of solutes in

Correspondence: Dr Robert Guei, WARDA 01 BP 2551, Bouake 01, Cote D'Ivoire, West Africa.

*Contribution no. 93-98-J from the Kansas Agric. Exp. Stn., Manhattan, KS 66506 , U.S.A. Part of a dissertation submitted by Robert G. Guei in partial fulfilment of the requirements for the PhD degree. response to water deficits or salinity (Turner \& Jones, 1980). The maintenance of turgor pressure as the plant water potential declines is crucial for cell expansion, growth, and many of the associated biochemical, physiological, and morphological processes (Jones et al., 1981). McCree (1986) suggested that greater osmotic adjustment arises from the reduction in leaf growth rate at higher leaf water potentials than photosynthesis, thereby leading to a passive accumulation of solutes as the production of assimilates exceeds the demand for growth. In addition, osmotic adjustment has been shown to maintain higher stomatal conductance. Turner et al. (1978) noted the maintenance of stomatal conductance of $0.17 \mathrm{~cm} \mathrm{~s}^{-1}$ at low water potentials in osmotically adjusted sorghum and sunflower plants. Therefore, maintenance of higher leaf conductance at the low water potential by osmotic adjustment would maintain high rates of photosynthesis.

A wide variety of solutes has been reported to accumulate in plant tissues during water stress, resulting in osmotic adjustment. Many of these are common 
metabolites such as sugars, amino acids, and organic acids. Others are nitrates, chloride, and potassium ions (Morgan, 1984).

Considerable work has been done showing substantial differences in turgor maintenance in different species at low water potentials. Genetic variation for osmotic adjustment has been reported in wheat (Morgan, 1977, 1983; Johnson et al., 1984; Morgan et al., 1986), sorghum (Ackerson et al., 1980; Shackel et al., 1982; Wright \& Smith, 1983); millet (Henson, 1982; Henson et al., 1982); rice (Turner et al., 1986); cotton (Karami, et al., 1980) and barley (Blum, 1989). However, little is known about the genetics of osmotic adjustment in tropical lowland maize. The choice of breeding methods for genetic improvement of a crop depends upon the presence of genetic variability and its nature and magnitude (Shahi \& Singh, 1985). Selection for osmotic adjustment requires knowledge and understanding of the genetic mechanisms governing the expression of the trait and the amount of genetic variability present in the plant populations under selection. In addition, knowledge of the relative magnitude and importance of additive and dominant gene actions and their interactions with the environment aids plant breeders in the development of breeding schemes or the choice of materials from the germplasm pool for population improvement (Shahi \& Singh, 1985).

This study was initiated:

1 to quantify the amount of genetic variability present in two tropical lowland maize populations for osmotic adjustment.

2 To estimate its heritability and the relative importance of additive and dominant components of variance for the choice of breeding methods more appropriate in making gains from selection.

3 To determine the importance of osmotic adjustment in breeding tropical maize for drought tolerance.

\section{Materials and methods}

The study was conducted at the International Center for Corn and Wheat Improvement (CIMMYT) in Mexico in 1989-1990. Two elite maize populations from CIMMYT (Laposta Sequia and Pool 26 Sequia) were used. Laposta Sequia is a late (120 days' maturity), lowland, tropical, white dent, often used in breeding programmes in West Africa for its resistance to maize streak virus. Pool 26 Sequia is a late (115 days' maturity) lowland, tropical, yellow flint/dent that is resistant to ear rots.

Non-inbred $\left(\mathrm{S}_{0}\right)$ plants of Laposta Sequia and Pool 26 Sequia were planted in a breeding nursery at Poza Rica, Mexico in November 1988. Using the Design I mating system (Nested Design) introduced by
Comstock \& Robinson (1948), randomly selected males from each population (45 from Laposta Sequia and 42 from Pool 26 Sequia) were crossed to two randomly selected and unrelated female plants.

Progenies from Laposta Sequia (90 full-sib families) and Pool 26 Sequia ( 84 full-sib families) were evaluated at two locations for two seasons. The first evaluation was planted May 15, 1989 at the Poza Rica CIMMYT station (latitude $20^{\circ} 32^{\prime} \mathrm{N}$, longitude $97^{\circ} 26^{\prime} \mathrm{W}$; elevation $60 \mathrm{~m}$ ). Mean maximum and minimum temperatures during the growing season were $33.6^{\circ} \mathrm{C}$ and $22.5^{\circ} \mathrm{C}$ respectively (Table 1 ). Rainfall during the test period was $794.6 \mathrm{~mm}$ which was slightly less than the 10 year average of $842.1 \mathrm{~mm}$. The second trial, planted on November 15, 1989, was conducted in 1990 in the dry winter season at Tlaltizapan, Morelos, Mexico (latitude $18^{\circ} 41^{\prime} \mathrm{N}$, longitude $99^{\circ} 08^{\prime} \mathrm{W}$; elevation 940 $\mathrm{m})$. Mean temperatures for the growing season were $32.1^{\circ} \mathrm{C}$ maximum and $12^{\circ} \mathrm{C}$ minimum. Rainfall during the test period at this site was $37.1 \mathrm{~mm}$; thus plant growth depended on stored and applied water.

Plants were grown under two water regimes, i.e. rainfed and irrigated. The two-row plots $(2.5 \mathrm{~m}$ long $)$ with inter-row spacing of $75 \mathrm{~cm}$ were replicated twice. A split plot arrangement in Replication in Block Design (randomized incomplete-block design) was used after subdividing the males into sets or subgroups (nine sets each of five different males for Laposta and seven sets each of six males for Pool 26). The sets were randomly allocated to blocks as were progeny rows within each set. Water regimes were main plots, and families were subplots. A furrow irrigation system was used to apply $80 \mathrm{~mm}$ of water per application over all treatments at both locations during the first 3 weeks following germination to ensure good stands. Irrigation was continued in the control treatments every 2 weeks but no water was supplied for the stress treatments during the remainder of the growing period. Two seeds per hill were planted and plots were later thinned to obtain the required plant density $(53,333$ plants $\left.\mathrm{ha}^{-1}\right)$. Sixteen competitive plants were chosen at random in each plot for recording observations. Data were taken on grain yield, number of ears per plant, days to 50 per cent anthesis, silking (Guei \& Wassom, 1992) and chlorophyll fluorescence but those data are not a part of this report. Plot sampling for water potential was done at two growth stages and at predawn $(0500-0700 \mathrm{~h})$ the following day after irrigation (full turgor). The first sampling was done at the vegetative stage about 4 weeks before anthesis and the second measurement during flowering. Samples consisted of two leaf discs $(5 \mathrm{~cm}$ in diameter) collected per plant on the uppermost, fully expanded leaf. Sixteen plants were used per plot. A total of 32 discs per plot were 
Table 1 Monthly maximum and minimum temperature averages, monthly and total rainfall for the two growing seasons at the Tlaltizapan and Poza Rica sites in Mexico

\begin{tabular}{|c|c|c|c|c|c|c|}
\hline & \multicolumn{4}{|c|}{ Average monthly temperature } & \multicolumn{2}{|c|}{ Rainfall } \\
\hline & $\operatorname{Max}{ }^{\circ} \mathrm{C}$ & $\begin{array}{l}10 \mathrm{yr} \\
\text { ave. }\end{array}$ & $\operatorname{Min}{ }^{\circ} \mathrm{C}$ & $\begin{array}{l}10 \mathrm{yr} \\
\text { ave. }\end{array}$ & $\mathrm{mm}$ & $\begin{array}{l}10 \mathrm{yr} \\
\text { ave. }\end{array}$ \\
\hline \multicolumn{7}{|l|}{ Poza Rica } \\
\hline May 1989 & 35.6 & 33.3 & 22.8 & 22.2 & 35.2 & 99.1 \\
\hline June 1989 & 35.4 & 33.0 & 23.2 & 22.2 & 150.4 & 183.8 \\
\hline July 1989 & 33.1 & 32.5 & 22.8 & 21.7 & 178.3 & 136.7 \\
\hline Augt 1989 & 32.6 & 32.8 & 22.6 & 21.7 & 125.3 & 196.6 \\
\hline Sept 1989 & 31.2 & 32.0 & 21.1 & 21.2 & 305.4 & 225.9 \\
\hline Average temp. & 33.6 & 32.7 & 22.5 & 21.8 & & \\
\hline Total rainfall & & & & & 794.6 & 842.1 \\
\hline \multicolumn{7}{|l|}{ Tlaltizapan } \\
\hline Nov 1989 & 31.4 & 30.5 & 12.6 & 11.6 & 1.0 & 5.8 \\
\hline Dec 1989 & 29.3 & 30.0 & 9.7 & 9.6 & 4.8 & 3.9 \\
\hline Jan 1990 & 31.4 & 30.0 & 9.3 & 8.8 & 1.3 & 11.9 \\
\hline Feb 1990 & 31.9 & 31.6 & 11.4 & 10.4 & 6.1 & 2.9 \\
\hline Mar 1990 & 33.4 & 33.6 & 13.3 & 12.7 & 1.0 & 6.0 \\
\hline Apr 1990 & 35.6 & 35.2 & 15.5 & 15.9 & 22.9 & 8.1 \\
\hline Average temp. & 32.1 & 31.8 & 12.0 & 11.5 & & \\
\hline Total rainfall & & & & & 37.1 & 38.6 \\
\hline
\end{tabular}

immediately wrapped in a plastic bag to avoid transpiration and then frozen at $-18^{\circ} \mathrm{C}$ for 1 to 2 days. After discs were thawed, leaf sap was extracted from a bulk plot sample using a mechanical device designed by the CIMMYT maize programme. The osmotic potential was immediately measured with a vapour pressure osmometer (Wescor model 5100B, Logan, Utah). The difference in water potential between stressed and non-stressed treatments was considered as osmotic adjustment.

Analyses of variance for plot averages at each growth stage were performed as suggested by Hallauer \& Miranda (1988). Variance components caused by males $\left(\sigma_{m}^{2}\right)$, females within males $\left(\sigma_{f / m}^{2}\right)$ and their interactions with environments $\left(\sigma_{e m}^{2}, \sigma_{e f / m}^{2}\right)$ were computed from the analysis of variance table (Table 2) using observed and expected mean squares. These components were used to estimate additive genetic variance $\left(\sigma_{\mathrm{A}}^{2}\right)$, dominance variance $\left(\sigma_{\mathrm{D}}^{2}\right)$, and their standard errors, ratio of dominance variance to additive variance, and narrow sense heritability, as estimated by Hallauer \& Miranda (1988):

$\sigma_{A}^{2}=4 \sigma_{m}^{2}$ for non-inbred plant (the inbreeding coefficient $F=0$ );

$\sigma_{\mathrm{D}}^{2}=4 \sigma_{f / m}^{2}-4 \sigma_{m}^{2}$.

The standard errors of estimates of variance were computed by taking the square root of the variance of the estimates. From Table 2 the estimated variance of $\sigma_{\AA}^{2}$ is:

$V\left(\sigma_{\mathrm{A}}^{2}\right)=\frac{16 \times 2}{e^{2} r^{2} f^{2}}\left(\frac{M_{5}^{2}}{\text { d.f. } ._{5}+2}+\frac{M_{4}^{2}}{\text { d.f. }_{4}+2}+\frac{M_{3}^{2}}{\text { d.f. }_{3}+2}+\frac{M_{2}^{2}}{\text { d.f. }{ }_{2}+2}\right)$.

$M_{2}, M_{3}, M_{4}$, and $M_{5}$ are observed mean squares in Table 2. d.f. , d.f. $_{3}$, d.f. . , and d.f. 5 are degrees of freedom associated with $M_{2}, M_{3}, M_{4}$, and $M_{5}$, respectively. The estimated variance of $\sigma_{\mathrm{D}}^{2}$ is:

$$
\begin{aligned}
V\left(\sigma_{\mathrm{D}}^{2}\right) & =\frac{16 \times 2}{e^{2} r^{2} f^{2}}\left[\frac{M_{5}^{2}}{\text { d.f. }{ }_{5}+2}+\frac{M_{4}^{2}\left(f^{2}+1\right)}{\text { d.f. } ._{4}+2}+\frac{M_{3}^{2}}{\text { d.f. } \cdot 2}+2\right. \\
& \left.+\frac{M_{2}^{2}\left(f^{2}+1\right)}{\text { d.f. } ._{2}+2}\right] .
\end{aligned}
$$

Narrow sense heritability among full-sib families was computed as follows:

$h^{2}=\frac{4 \sigma_{m}^{2}}{\sigma_{\mathrm{e} / \mathrm{re}}^{2}+4 \sigma_{\mathrm{c} f / m / e}^{2}+4 \overline{\sigma_{f / m}^{2}}}$,

where: $e=$ number of environments; $r=$ number of replications; $\sigma_{\mathrm{e}}^{2}=$ error variance.

In this study we assumed a random mating population in linkage equilibrium, and the absence of epistasis. Genetic coefficient of variation $\left(\mathrm{cv}_{\mathrm{g}}\right)$ was calculated 
Table 2 Analyses of variance for traits measured

\begin{tabular}{|c|c|c|c|}
\hline Source of variation & d.f. & M.S. & Expected M.S. \\
\hline Environments & $e-1$ & & \\
\hline Sets & $s-1$ & & \\
\hline Environments $\times$ sets & $(e-1)(s-1)$ & & \\
\hline $\begin{array}{l}\text { Replications in sets in } \\
\text { environments }\end{array}$ & $e s(r-1)$ & & \\
\hline Male in sets & $s(m-1)$ & $M_{5}$ & $\begin{array}{l}\sigma_{e}^{2}+r \sigma_{e f / m}^{2}+r f \sigma_{e m}^{2} \\
+r e \sigma_{f / m}^{2}+r e f \sigma_{m}^{2}\end{array}$ \\
\hline Females in males in sets & $m s(f-1)$ & $M_{4}$ & $\sigma_{e}^{2}+r \sigma_{e f / m}^{2}+r e \sigma_{f / m n}^{2}$ \\
\hline $\begin{array}{l}\text { Environments } \times \text { males in } \\
\text { sets }\end{array}$ & $s(m-1)(e-1)$ & $M_{3}$ & $\sigma_{e}^{2}+r \sigma_{e f / m}^{2}+r f \sigma_{e m}^{2}$ \\
\hline $\begin{array}{l}\text { Environments } \times \text { females in } \\
\text { males in sets }\end{array}$ & $m s(f-1)(e-1)$ & $M_{2}$ & $\sigma_{e}^{2}+r \sigma_{e f / m}^{2}$ \\
\hline Error & $e s(r-1)(m f-1)$ & $M_{1}$ & $\sigma_{e}^{2}$ \\
\hline Total & sermf- 1 & & \\
\hline
\end{tabular}

$r=$ number of replications; $f=$ number of females per male; $s=$ number of sets; $e=$ number of environments; $m=$ number of males in a set; $\sigma_{e}^{2}=$ environmental variance due to plots; $\sigma_{m}^{2}=$ component of variance due to males; $\sigma_{f / m}^{2}=$ component of variance due to females within males; $\sigma_{e m}^{2}=$ component of variance due to the interaction of males with environment; $\sigma_{e f / m}^{2}=$ component of variance due to the interaction of females within males with environment.

Table 3 Additive $\left(\sigma_{\AA}^{2}\right)$ and dominance $\left(\sigma_{\mathrm{D}}^{2}\right)$ variances, their interactions with environments $\left(\sigma_{\mathrm{A} e}^{2}, \sigma_{\mathrm{D} e}^{2}\right)$, heritability $\left(h^{2}\right)$, genetic coefficient of variation $\left(\mathrm{cv}_{\mathrm{g}}\right)$, and the ratio of dominance variance to additive variance $\left(\sigma_{\mathrm{D}}^{2} / \sigma_{\mathrm{A}}^{2}\right)$ for osmotic adjustment measured at the vegetative stage (OS1) and at flowering stage (OS2) in Pool 26 Sequia

\begin{tabular}{cccccccc}
\hline & \multicolumn{1}{c}{$\sigma_{\mathrm{A}}^{2}$} & \multicolumn{1}{c}{$\sigma_{\mathrm{A} e}^{2}$} & $\sigma_{\mathrm{D}}^{2}$ & \multicolumn{1}{c}{$\sigma_{\mathrm{D} e}^{2}$} & $h^{2}(\%)$ & $\mathrm{cv}_{\mathrm{g}}(\%)$ & $\sigma_{\mathrm{D}}^{2} / \sigma_{\mathrm{A}}^{2}$ \\
\hline OS1 & 189 & $1546^{* *}$ & $413^{*}$ & -1612 & 8 & 3.2 & 2.17 \\
& \pm 221 & \pm 241 & \pm 305 & \pm 351 & & & \\
OS2 & $413^{*}$ & -65 & $1618^{* *}$ & -1444 & 12 & 4.5 & 3.91 \\
& \pm 380 & \pm 303 & \pm 605 & \pm 576 & & & \\
\hline
\end{tabular}

*,**, significant at 0.05 and 0.01 levels, respectively.

as

$\left(\sqrt{V_{\mathrm{g}}} / \bar{x}\right) \times 100$

where $V_{\mathrm{g}}$ is the genetic variance, and $\bar{x}$ is the mean of a trait (Kang et al., 1990). Genotypic and phenotypic correlations were computed according to Robinson et al. (1951) as follows:

${ }^{r} \mathrm{p}_{\mathrm{xy}}=\frac{\mathrm{COVp}_{\mathrm{xy}}}{\sqrt{\sigma_{\mathrm{px}}^{2} \mathrm{x} \sigma_{\mathrm{py}}^{2}}}$ and $^{r} \mathrm{~g}_{\mathrm{xy}}=\frac{\mathrm{COVg}_{\mathrm{xy}}}{\sqrt{\sigma_{\mathrm{gx}}^{2} \mathrm{x} \sigma_{\mathrm{gy}}^{2}}}$,

where: ${ }^{r} \mathrm{p}_{\mathrm{xy}}=$ phenotypic correlation between trait $\mathrm{x}$ and trait $\mathrm{y} ;{ }^{r} \mathrm{~g}_{\mathrm{xy}}=$ genotypic correlation between trait $\mathrm{x}$ and trait $y ; C O V p_{x y}=$ phenotypic covariance between trait $\mathrm{x}$ and trait $\mathrm{y}$; $\mathrm{COVg}_{\mathrm{xy}}=$ genotypic covariance between trait $\mathrm{x}$ and trait $\mathrm{y} ; \sigma_{\mathrm{px}}^{2}=$ phenotypic variance of trait $\mathrm{x} ; \sigma_{\mathrm{py}}^{2}=$ phenotypic variance of trait $\mathrm{y} ; \sigma_{\mathrm{gx}}^{2}=$ genotypic variance of trait $\mathrm{x} ; \sigma_{\mathrm{gy}}^{2}=$ genotypic variance of trait y.

Data from each sample of progenies in each population were analysed. The form of the analysis is given in Table 2 .

\section{Results and discussion}

\section{Pool 26 Sequia}

Estimates of genetic variance (Table 3 ) indicated that at both the vegetative (OS1) and the flowering stages (OS2), variance from dominant effects was more 
important in the expression of osmotic adjustment trait than that from additive effects. However, the magnitude of the additive and the dominant gene actions was greater at OS2 than at OS1. Drought stress was greater during later stages of plant growth at the test locations (Table 1), and, as confirmed by previous results, more genetic variability was present in this population under drought stress than non-stress environments for yield, number of ears per plant and anthesis-silking interval (Guei \& Wassom, 1992).

Larger standard errors were obtained for $\sigma_{\mathrm{D}}^{2}$. This is usually expected from studies that used the Design I mating scheme, because of the complex function used to make the estimate (Hallauer \& Miranda, 1988). Interactions between variance estimates and the environments were not significant $(P>0.05)$ except for $\sigma_{A e}^{2}$ at the vegetative stage $(P<0.01)$, indicating that the degree of expression of the variance estimates remained the same from location to location. Heritability estimates and the genetic coefficient of variation $\left(\mathrm{cv}_{\mathrm{g}}\right)$ were very small, indicating that not much genetic variation was present for the trait. For selection purposes, additive genetic variance is of primary importance, and thus little progress should be expected from selection for osmotic adjustment in this population. The lack of genetic variability for this trait in tropical lowland maize was reported earlier by J. Bolaños and

Table 4 Phenotypic and genotypic correlations between yield, OS1 and OS2 in Pool 26 Sequia and Laposta Sequia

\begin{tabular}{llllll}
\hline \multicolumn{2}{l}{ Pool 26 Sequia } & & \multicolumn{2}{l}{ Laposta Sequia } \\
& Phenotypic & Genotypic & & Phenotypic & Genotypic \\
\hline OS1 & 0.07 & 0.26 & 0.06 & 0.22 \\
OS2 & 0.11 & 0.38 & 0.22 & 0.32 \\
\hline
\end{tabular}

G. O. Edmeades at CIMMYT (personal communication, 1990).

Ratios of dominance to additive genetic variance estimates at both OS1 and OS2 were greater than 0.5 (complete dominance), indicating overdominance (Robinson et al., 1960). In addition, phenotypic and genotypic correlations between osmotic adjustment and yield were small and non-significant (Table 4).

\section{Laposta Sequia}

Additive and dominance variance estimates in Table 5 indicated that more genetic variation was present in OS2 than OS1, when no or very little genetic variability was expressed. Dominant gene action was more important in the expression of the trait than additive genetic effect. However, all variance estimates in OS1 and their interactions with environments were negative. Negative estimates could be obtained if the true values of the variance were zero or very small positive quantities, because variances by definition are never negative (Robinson et al., 1955). Errors in sampling and failure to achieve random mating could cause negative variances. This may have been the case in this study, where male and female parents were planted at the same time. Matings involving early-, intermediate-, and late-flowering males may have been largely restricted to early-, intermediate-, and late-silking females respectively. A negative heritability estimate was obtained at OS1 and reported as zero. Genetic coefficient of variation was small at both stages, but higher at OS2 than OS1. Similar results were obtained earlier in Pool 26 Sequia. The variance ratios, like in Pool 26 Sequia, were greater than 0.5 suggesting that overdominance was a major cause of genetic variation in osmotic adjustment.

Phenotypic and genotypic correlations were positive but non-significant. Correlations were higher at OS2 than OS1, as obtained earlier in Pool 26 Sequia.

Table 5 Additive $\left(\sigma_{A}^{2}\right)$ and dominance $\left(\sigma_{\mathrm{D}}^{2}\right)$ variances, their interactions with environments $\left(\sigma_{\mathrm{A} e}^{2}, \sigma_{\mathrm{D} e}^{2}\right)$, heritability $\left(h^{2}\right)$, genetic coefficient of variation $\left(\mathrm{cv}_{\mathrm{g}}\right)$, and the ratio of dominance variance to additive variance $\left(\sigma_{\mathrm{D}}^{2} / \sigma_{\mathrm{A}}^{2}\right)$ for osmotic adjustment measured at the vegetative stage (OS1) and at flowering stage (OS2) in Laposta Sequia

\begin{tabular}{lccccccc}
\hline & \multicolumn{1}{c}{$\sigma_{\AA}^{2}$} & $\sigma_{\AA ⿻}^{2}$ & \multicolumn{1}{c}{$\sigma_{\mathrm{D}}^{2}$} & \multicolumn{1}{c}{$\sigma_{\mathrm{D} e}^{2}$} & $h^{2}(\%)$ & $\mathrm{cv}_{\mathrm{g}}(\%)$ & $\sigma_{\mathrm{D}}^{2} / \sigma_{\AA}^{2}$ \\
\hline OS1 & -14 & -743 & -42 & -3611 & 0 & 0.7 & 3.00 \\
& \pm 212 & \pm 303 & \pm 378 & \pm 562 & & & \\
OS2 & $657^{*}$ & 370 & $1575^{* *}$ & $1460^{*}$ & 9 & 4.2 & 2.39 \\
& \pm 405 & \pm 446 & \pm 640 & \pm 772 & & & \\
\hline
\end{tabular}

Significant at $0.05^{*}$ and $0.01^{* *}$ levels. 


\section{Summary}

The two elite tropical lowland maize populations used in this study are being developed at CIMMYT, Mexico for drought tolerance. Full-sib families developed from each population were evaluated. Results showed that the two populations were similar in terms of genetic variation for osmotic adjustment. In both populations dominant genetic effects were more important than additive effects in controlling the expression of the trait. However, more genetic variation was found during the flowering stage, when water stress was more severe, than at vegetative stage. But overall, very little genetic variability for osmotic adjustment was present in either population. In addition, the association between the trait and yield was weak. These findings agreed with studies performed by the CIMMYT maize programme, which found weak and inconsistent associations between osmotic adjustment and yield under drought in tropical lowland maize. Because of the lack of sufficient genetic variation, not much genetic gain should be expected from selection in these populations for osmotic adjustment. These results, although specific to these two populations and to particular environmental conditions, suggest the need for further investigations into the importance of additive and dominance genetic effects in controlling the expression of osmotic adjustment as a drought-adaptive trait in tropical lowland maize.

\section{References}

ACKERSON, R. C., KRIEG, D. R. AND SUNG, F. J. M. 1980. Leaf conductance and osmoregulation of field grown sorghum genotypes. Crop Sci., 20, 10-14.

BLUM, A. 1989. Osmotic adjustment and growth of barley genotypes under drought stress. Crop Sci., 29, 230-233.

COMSTOCK, R. E. AND ROBINSON, H. F. 1948. The components of genetic variances in populations of biparental and their use in estimating the average degree of dominance. Biometrics, 4, 254-266.

GUEI, R. G. AND WASSOM, C. E. 1992. Inheritance of some drought adaptive traits in maize: I. Interrelationships between yield, flowering, and ears per plant. Maydica, 37, 157-164.

HALlAUER, A. R. AND MIRANDA, J. B. 1988. Heredity variance: mating design. In: Hallaue, A. R. and Miranda, J. B. (eds) Quantitative Genetics in Maize Breeding, Iowa State University Press, Ames, pp. 45-114.

HENSON, I. E. 1982. Osmotic adjustment to water stress in pearl millet (Pernnissetum americanum (L.) Leeke) in a controlled environment. J. Exp. Bot., 33, 78-87.

HENSON, I. E., MAHALAKSMI, V., BIDINGER, F. R. AND ALGARSWAMI, G. 1982. Osmotic adjustment to water stress in pearl millet under field conditions. Plant Cell Environ., 5, 147-154.

JOHNSON, D. A., NGUYEN, H. T. AND CROY. L. I. 1984. Osmotic adjustment and solute accumulation in two wheat genotypes differing in drought resistance. Crop Sci., 24, 957-962.
JONES, M. M., TURNER, N. C. AND OSMOND, C. B. 1981. In: Paleg, L. G. and Aspinall, D. (eds) The Physiology and Biochemistry of Drought Resistance in Plants, Wiley Interscience, New York, pp. 15-38.

KANG, M. S., SOSA, O. JR. AND MILLER, J. D. 1990. Genetic variation and advance for ring hardiness, flowering, and sugar yield traits in sugarcane. Field Crop Res., 23, 63-73.

KARAMI, E., KRIEG, D. R. AND QUISEBERRY, J. E. 1980. Water relations and carbon-14 assimilation of cotton with different leaf morphology. Crop Sci., 20, 421-426.

McCREE, K. J. 1986. Whole plant carbon balance during osmotic adjustment to drought and salinity stress. Aust. J. Plant Physiol., 13, 33-45.

MORGAN, J. M. 1977. Differences in osmoregulation between wheat genotypes. Nature, 270, 234-235.

MORGAN, J. M. 1983. Osmoregulation as a selection criterion for drought tolerance in wheat. Aust. J. Agric. Res., 34, 607-614.

MORGAN, J. M. 1984. Osmoregulation and water stress in higher plants. Ann. Rev. Plant Physiol., 35, 299-319.

MORGAN, J. M., HARE, R. A. AND FLETCHER, R. J. 1986. Genetic variation in osmoregulation in bread and durum wheats and its relationship to grain yield in a range of field environments. Aust. J. Agric. Res., 37, 449-457.

ROBINSON, H. F., COMSTOCK, R. E. AND HARVEY, P. H. 1951. Genotypic and phenotypic correlations in corn and their implications in selection. Agron. Jour., 43, 282-287.

ROBINSON, H. F., COMSTOCK, R. E. AND HARVEY, P. H. 1955. Genetic variances in open-pollinated varieties of corn. Genetics, 40, 45-60.

ROBINSON, H. F., COCKERHAM, C. C. AND MOLL, R. H. 1960. Studies on estimation of dominance variance and effects of linkage bias. In: Kempthorne, O. (ed.) International Series of Monographs on Biometry. Proceedings of an International Symposium at Ottawa, August, 1958, pp. 171-177.

SHACKEL, K. A., FOSTER, K. W. AND HALL, A. E. 1982. Genotypic differences in leaf osmotic potential among grain sorghum cultivars grown under irrigation and drought. Crop Sci., 22, 1121-1125.

SHAHI, J. P. AND SINGH, I. S. 1985. Estimation of genetic variability for grain yield and its components in a random mating population of maize. Crop Improv., 12, 126-129.

TURNER, N. C., BEGG, J. E. AND TONNETT, M. L. 1978. Osmotic adjustment of sorghum and sunflower crops in response to water deficits and its influence on the water potential at which stomata close. Aust. J. Plant Physiol., 5, 597-608.

TURNER, N. C. AND JONES, M. M. 1980. Turgor maintenance by osmotic adjustment: A review and evaluation. In: Turner, N. C. and Kramer P. J. (eds) Adaptation of Plants to Water and High Temperature Stress, Wiley Interscience, New York, pp. 38-42.

TURNER, N. C., OTOOLE, J. C., CRUZ, R. T., YAMBOA, S. A., NAMUCO, O. S. AND DINGKUHN, M. 1986. Responses of seven diverse rice cultivars to water deficits. II. Osmotic adjustment, leaf elasticity, leaf extension, leaf death, stomatal conductance and photosynthesis. Field Crop Res., 13, 273-286.

WRIGHT, G. C. AND SMITH, C. G. 1983. Differences between two grain sorghum genotypes in adaptation to drought stress. II. Root water uptake and water use. Aust. J. Agric. Res., 34, 627-636. 